\title{
Nanokatal per Liter
}

National Cancer Institute

\section{Source}

National Cancer Institute. Nanokatal per Liter. NCI Thesaurus. Code C70510.

A unit of catalytic activity concentration defined as the catalytic activity of the component equal to one billionth of katal (10E-9 katal) in the unit volume of the system equal to one liter. 